\section{Response to Zlotogora and Meiner}

We appreciate the thoughtful letter "Ashkenazi carrier screening for reproductive planning: is this what we planned for?", by Joël Zlotogora and Vardiella Meiner. ${ }^{1}$ We answer with a resounding "Yes." It was our intent to present an updated panel that could be used not only for reproductive planning but also for early diagnosis and intervention. "Expanded Genetic Screening Panel for the Ashkenazi Jewish Population"2 responds to what our patients have told us that they want ${ }^{3}$ as well as to the recommendation of the American College of Medical Genetics and Genomics: to provide information about actionable variants when such information becomes available from genetic testing. ${ }^{4}$ Patients receiving genetic counseling can choose the conditions for which they want testing and those for which they do not.

To address the accuracy of annotation and the severity of phenotypes, we performed our own independent consensus review because we observed that ClinVar annotations were often internally discordant. We acknowledge that future revisions will be made because some conditions are found to be exceedingly rare or because clinical utility is not observed. As more sequencing and improved annotation is achieved, this expanded panel will be expanded even more.

\section{DISCLOSURE}

The authors declare no conflict of interest.

Brett Baskovich, $M D^{1}$, Susan Hiraki, $M S^{2}$,

Carole Oddoux, $P h D^{1,2}$, Harry Ostrer, $M D^{1,2}$ and

Kinnari Upadhyay, $M S^{2}$

${ }^{1}$ Department of Pathology, Montefiore Medical Center, Bronx, New York, USA; ${ }^{2}$ Department of Pathology, Albert Einstein College of Medicine of Yeshiva University,

Bronx, New York, USA Correspondence: Harry Ostrer (harry.ostrer@einstein.yu.edu)

\section{REFERENCES}

1. Zlotogora J, Meiner V. Ashkenazi carrier screening for reproductive planning: is this what we planned for? Genet Med 2016;18:529.

2. Baskovich B, Hiraki S, Upadhyay K, et al. Expanded genetic screening panel for the Ashkenazi Jewish population. Genet Med; e-pub ahead of print 3 September 2015

3. Hathaway $\mathrm{F}$, Burns $\mathrm{E}$, Ostrer $\mathrm{H}$. Consumers' desire towards current and prospective reproductive genetic testing. J Genet Couns 2009;18:137-146.

4. Green RC, Berg JS, Grody WW, et al.; American College of Medical Genetics and Genomics. ACMG recommendations for reporting of incidental findings in clinical exome and genome sequencing. Genet Med 2013;15:565-574.

Advance online publication 10 December 2015. doi:10.1038/gim.2015.170 